\title{
El problema de la conciencia en Los errores de José Revueltas
}

Evodio Escalante Universidad Autónoma Metropolitana

Resumen

Los errores es la gran novela que José Revueltas estaba destinado a escribir. En ella se concentra su etapa de madurez intelectual, filosófica y literaria. "El hombre es un ser erróneo y en eso radica su condición trágica” — dice Jacobo Ponce, personaje de la novela y alter ego de Revueltas. Reducir el error al grueso del ínfimo diámetro de un cabello, puesto en dimensiones cósmicas, se revela como un abismo puesto en relación con la categoría de saber absoluto que prefigura G. W. F. Hegel en su Fenomenología del espiritu. En este breve ensayo se da cuenta de las reflexiones intelectuales de Revueltas en torno a los postulados sobre la autoconciencia y el saber absoluto de Hegel.

Palabras clave: Los errores, Revueltas, autoconciencia, saber absoluto, Hegel.

\section{Abstract}

Los errores it's the great novel that Revueltas was bound to write some day. It reveals his intellectual, philosophical and literary maturity. In words of Jacobo Ponce — character in the novel and alter ego of Revueltas itself_: "the man is erroneous by nature; here's within his own tragedy". Diminish the error up to the thickness of a capillar hair's wide, in cosmic measures, means and reveals a huge gap fac- 
ing the absolute knowledge coined by H.W. Hegel itself. So, in this brief essay Revueltas utter's his owns intellectual thoughts bounding self-awareness and total knowledge within Hegel's mind.

Keywords: Los errores, Revueltas, Self-awareness, Total Knowledge, Hegel.

A nes la que nada, habría que comenzar diciendo que Los errores nado a escribir. Madurez ideológica, madurez filosófica, madurez vital, pero antes que ello y sobre todo, la madurez de un escritor en pleno dominio de su lenguaje y su universo narrativo. El eje de la novela, que se refleja en el título de la misma, es de pleno derecho una tesis filosófica no exenta de complejidades. Al suscribirla, el comunista que era entonces Revueltas introduce en el centro de su argumentación una variante que lo convierte en un disidente no sólo del marxismo oficial, sino del marxismo a secas. Tanto la fe dogmática como la verdad satisfecha de sí quedan excluidas, por principio, de este discurso cuando Jacobo Ponce, el alter ego del autor en la novela, escribe: "El hombre es un ser erróneo [...]; un ser que nunca terminará por establecerse del todo en ninguna parte: aquí radica precisamente su condición revolucionaria y trágica, inapacible." El punto preciso en que el hombre podrá realizarse por fin como especie dotada de razón implica saturar un resquicio acaso milimétrico, como del grueso de un cabello, pero que por esto mismo se revela como insaturable por definición, pues "dejará siempre sin cubrir la coincidencia máxima del concepto con lo concebido, de la idea con su objeto: reducir el error al grueso de un cabello constituye así, cuando mucho, la más alta victoria que puede obtener". El grueso de un cabello se revela en realidad, dentro de las dimensiones cósmicas, como un abismo sin medida que suscita en el personaje una suerte de delirio filosofante, por el que llega a imaginar que podríamos encontrarnos algún día con 
unos seres absolutamente racionales que nos estarían esperando en el porvenir para que nos reconociéramos en ellos, como si la humanidad como un todo trascendiera los remanentes de animalidad y accediera por fin al saber absoluto que prefigura Hegel en su $\mathrm{Fe}$ nomenología del espiritu. Lo más grave es que este error milimétrico, según Jacobo Ponce, no sólo pervertiría la conciencia humana, excluida por ello para siempre de la verdad, sino que contaminaría el espacio y la materia misma que nos constituye. Este hueco imposible de calcular "es también el error de la materia, y por ende, ahí nacerán, de modo inexorable, otros seres racionales de los que acaso lleguemos a saber algo, quién sabe en qué remoto y desventurado día” (Revueltas, 1964: 78-79).

"Metafísico estáis." — “Es que soy hegeliano”, respondería Revueltas. La conciencia del hombre, con la miseria o la grandeza que queramos atribuirle, queda así confrontada, no importa que sólo de modo imaginario, y siempre dentro del ensayo que Ponce redacta en la novela, con la conciencia de unos extraterrestres que el texto bautiza raciomorfos, encarnación posible de una razón que se habría realizado plenamente como razón en algún punto hipotético de un porvenir que, hoy por hoy, la historia parece obturar de manera obstinada. Basta empero con imaginar esta creatura raciomorfa para que el orgullo racional de los hombres que todos somos quede humillado y sujeto a una suerte de bufonería histórica de carácter trascendental. Antídoto contra el dogmatismo y las certezas ideológicas, este conflicto irresoluble entre el hombre y la realidad lo elabora Revueltas, no a partir de Marx, por supuesto, ni siquiera de Hegel mismo, de quien se declara admirador, sino de Alexandre Kojève. En alguna de sus lecciones parisinas de los años treinta en torno a la Fenomenología del espiritu de Hegel, llegó a sostener Kojève: "Esa oposición, ese conflicto entre el Hombre y lo Real dado, se manifiesta en primer término por el carácter erróneo del discurso revelador humano, y es sólo al final de los tiempos, al 
término de la Historia, cuando el Discurso del Sabio se une a la realidad" (2006, 47). ${ }^{1}$ Me parece evidente que la idea del error constitutivo del hombre que sólo habría de curarse con el supuesto advenimiento del saber absoluto lo ha tomado Revueltas de aquí.

Las complejidades y hasta las alucinaciones ideológicas de Jacobo Ponce, contenidas en el capítulo VII, contrastan con la peculiar estrategia realista que impera en la estructura general de la novela. Más allá de que ésta funciona como un gran mural histórico que retrata la vida en México en los ańos treinta del siglo pasado, como una crítica de las deformaciones que experimentan el socialismo y en general los militantes comunistas bajo la tutela del régimen soviético durante la época de la dictadura estalinista; más allá de que quede vibrando en la lectura la gran pregunta, formulada de manera expresa por el narrador, de si el siglo XX pasará a la historia como el siglo de la Revolución de Octubre o como el de los infames Procesos de Moscú, en los que decenas y decenas de altos cuadros del Partido fueron acusados de ser espías de Hitler y de haberse puesto al servicio del enemigo burgués; más allá de esto y de la innegable cuota de desencanto que esta visión implacable pudiera acarrear, Los errores permanece para mí como la obra de arte más ambiciosa, y mejor lograda, que Revueltas llegó a escribir. Es su contribución al arte de la novela en nuestro país.

Los hábitos académicos y cierta inercia del pensamiento, hasta cierto punto explicable en un texto de esta naturaleza, nos obligan

${ }^{1}$ Las conferencias de Kojève sobre La fenomenología del espiritu de Hegel tuvieron lugar en la Escuela de Altos Estudios de Paris entre 1933 y 1939. La declinación "hegeliana" del marxismo de Revueltas deriva, como lo ha mostrado Jorge Fuentes Morúa, de su descubrimiento en los años treinta de los Manuscritos económico-filosóficos (1844) de Marx, texto muy cercano a la lectura de la Fenomenología, lo que en buena medida explica que el concepto dominante en el texto de Marx sea el de la enajenación, no sólo del trabajo, sino del hombre como ser genérico frente a la naturaleza y frente a sí mismo en tanto especie racional. Vid. Jorge Fuentes Morúa, José Revueltas. Una biografía intelectual (2001). 
a ver Los errores como una suerte de manifiesto ideológico de su autor. Lo que llevo expuesto parecería corroborar esta tendencia que, empero, le hace un flaco favor a la novela en tanto novela. Terminamos leyendo el texto como si fuera un documento, o sea, como el vehículo de una información histórica e ideológica con la que podemos estar o no de acuerdo, y se nos olvida que lo que Revueltas puso en nuestras manos es antes que nada un monumento, quiero decir, un constructo semiótico que consta de múltiples estratos y que no puede ser reducido tan sólo al de su mensaje más evidente. Las complejidades arquitectónicas del monumento tendrían que ser incompatibles con una lectura lineal del mismo.

Lo que hay que señalar es que la prosa de Los errores es una de las mejores prosas que uno pueda encontrar en la narrativa mexicana del siglo XX. Los temas pueden haber envejecido, la ciudad misma que se describe en ella ha cambiado de modo radical, pero mientras haya alguien que aprecie el arte de la novela y sepa disfrutar del ritmo y de la densidad, lo mismo conceptual que afectiva, de la prosa, Los errores seguirá teniendo lectores. El arte de la novela remite no sólo a una fluidez de la acción y a una verosimilitud de lo relatado, tiene también que ver con la estructura total del texto, con la forma de enlazar los episodios de la trama y de interconectarlos entre sí, al grado que acaban fundiéndose. Como hace Faulkner en Las palmeras salvajes, la novela alterna y entreteje dos historias que en apariencia no tendrían nada que ver entre sí: la historia del robo del prestamista Victorino, en el barrio de la Merced (tramado por un padrote a quien apodan El Muñeco), y la del asalto al local de una organización derechista que tiene su sede en el centro histórico de la ciudad (ejecutado por un comando formado por integrantes del Partido Comunista). Esta duplicidad le permite dibujar, sobre el fondo claro-oscuro de la corrupción política y policiaca con que se gobierna este país, un retrato del modo de vida en que discurren los estratos lumpenizados de la sociedad al mismo tiempo que teje 
un prodigioso retrato de la situación de los militantes oprimidos por las estructuras dogmáticas de un Partido maquiavélico que no duda en encarcelar, "desaparecer" o liquidar físicamente a aquellos militantes que por una razón u otra se han convertido en indeseables.

El aspecto documental de la novela, quiero decir, su efectivo apego al referente histórico, nunca deja de estar en un primer plano. Aunque de modo formal Los errores está dedicada "a Imre Nagy el gran luchador húngaro", el verdadero "pivote" de la novela es la "desaparición forzada", en la Unión Soviética de los años de Stalin, del militante comunista Evelio Badillo, amigo muy cercano de José Revueltas — con quien había compartido la cárcel en Las Islas Marías - y que cayó en desgracia por motivos que se desconocen (acaso por haber borroneado en algún baño público una leyenda contra Stalin, en espańol, además, pensando que nadie la entendería). Después de años de confinamiento en Siberia, cuando incluso había olvidado ya a expresarse en su lengua materna, Badillo logra escapar y se presenta en la Embajada de México para pedir su repatriación. En la novela, este personaje que muere poco después de regresar a México de manera un tanto misteriosa lleva el nombre de Emilio Padilla.

Después de esta digresión obligada, retomo lo que pretendo destacar: el carácter magistral que exhibe la prosa de Revueltas en esta novela y que hay que colocar en un sitio todavía superior al que suelen otorgar los críticos a El apando (1969). Se trata de una prosa densa y nerviosa, demorada y envolvente pero fluida a la vez, reiterativa en el sentido musical del término, creadora de atmósferas así como plena de matices e inflexiones como lo exige la naturaleza de la técnica narrativa que domina en el texto: la narración omnisciente con focalización interna, la cual opera en lo básico a partir de vivificar la conciencia de cada uno de los personajes que van poblando el texto. Esta focalización rigurosa, cuyos antecedentes 
están lo mismo en Dostoyevski que en Proust, es lo que hace que esta novela se convierta no sólo en un lienzo social verosímil sino en una muy precisa indagación de los abismos subjetivos en los que las conjeturas, los miedos, los anhelos secretos y las prevenciones de la conciencia individual de cada uno llegan a ocupar el primer plano al grado de funcionar como pilares de la narración.

La técnica de la focalización interna resulta evidente desde el arranque mismo de la narración. Uno puede pensar, si se queda con las primeras líneas, que se trata de una narración objetiva, que contempla la realidad desde el exterior, sin involucrarse con ella, pero pronto habrá de advertir que no es así. Reproduzco el párrafo inicial para que se vea lo que intento mostrar:

Ahí a sus espaldas, visto en el cuadro del espejo, a unos cuantos pasos, entre las cobijas del camastro, dormía el pequeño cuerpo infantil, verdadero hasta lo alucinante, hasta la saciedad. Dentro de algunos minutos comenzarían todas las cosas, sin que ya nadie pudiera detenerlas, una detrás de otra, sometidas a su destino propio, extraordinarias y tangibles, más allá de esto, en una especie de infinito. Un infinito concreto e irreal como una borrachera. Comenzarían cuando se aproximara a despertarlo, esto era indudable. Cuando se aproximara a sacudir con la mejor de sus rabias, con ese odio, al pequeño cuerpo, para sacarlo de sus puercos sueños, los sueños viciosos en que estaría metido de la cabeza a los pies. El pequeño y sucio cuerpo de Elena.

Es la conciencia de Mario Cobián, por supuesto, la que asume la voz en este arranque de la novela. No estamos en aptitud de saber, como lectores, ni más ni menos que lo que conoce la conciencia del personaje, verdadera frontera y materia prima de lo que se relata. La argucia narrativa de Revueltas, empero, funciona de tal modo que esta subjetivación extremosa también, como de rebote, dice algo muy objetivo acerca de la novela: que estamos en el incipit, que ésta está por comenzar, que a partir de aquí la madeja se irá 
desatando sin que nadie pueda ya detener el hilo de los acontecimientos. La novela inicia pues con esta mirada que permite el espejo en la habitación del hotelucho donde Cobián, que se ha disfrazado de agente viajero para consumar el robo, se mira de modo narcisista en el espejo. Lo que descubre su mirada es el cuerpo dormido de su amigo y cómplice, el enano de circo, un homosexual que está enamorado de él, y a quien maliciosamente llama Elena, Elena-no.

La reflexividad y la subjetivación, propias no sólo de la conciencia en general sino de modo específico de la conciencia con conciencia de sí, sientan sus reales en esta novela en la que Revueltas recoge las lecciones de los grandes maestros a la vez que incorpora lo que su instinto de narrador ha procesado en sus lecturas de la Ciencia de la lógica y de la Fenomenología del espiritu, de Hegel. De este último libro, hasta donde alcanzo a ver, no le impresiona tanto la famosa dialéctica del amo y del esclavo que Hegel plantea como una lucha a muerte por el reconocimiento entre dos conciencias "enemigas", sino este planteamiento previo, acaso todavía más fundamental: que una autoconciencia sólo puede satisfacerse en otra autoconsciencia. Señala Hegel: "Con la autoconsciencia entramos $[\ldots]$ en el reino propio de la verdad". "De hecho - continúa Hegel—, la autoconsciencia es la reflexión, que desde el ser del mundo sensible y percibido, es esencialmente el retorno desde el ser otro" (1966: 107-108). La conciencia del otro se convierte, así, en el punto de partida de la verdadera conciencia de sí que no puede constituirse como tal sin este movimiento de regreso a partir de la conciencia del otro. La negatividad del otro hay que recuperarla y trabajarla en la conciencia de sí, como única forma de sobrevivencia. De aquí, concluye Hegel con este enunciado que no dejará nunca de ser inquietante: "La autoconsciencia sólo alcanza su satisfacción en otra autoconsciencia” (112). 
Cuando Margarita García Flores, que lo entrevista en Lecumberri, le pregunta: “¿Ha caído en la tentación de la novela-buzo?” Revueltas responde: "Me estoy aproximando a la concepción cabal de la novela-buzo, que tendería a ver al hombre como interioridad del ser humano. Esto es, a despecho de sus existencia social, en contraposición con ella, cualquiera que sea” (2001: 80). El acento lo pondría yo en la palabra interioridad y en lo que esta interioridad implica en el marco hegeliano de sus pesquisas: entre más se profundiza en una conciencia más se encuentra en ella la presencia de la conciencia del otro, y ello por la simple razón de que ese es su verdadero fundamento. Si le hacemos justicia a Los errores, tendríamos que tachar la expresión "me estoy aproximando" y afirmar que ella ya es un ejemplo logrado de esta novela-buzo por la que pregunta García Flores. Aunque por supuesto la acción narrativa propiamente dicha es la que proporciona el armazón de la misma, pues es la que constituye la trama, la sustanciosa "carne" del esqueleto la proporciona el discurso del narrador que se sumerge como quien nada en una piscina en las profundidades de la conciencia de sus diversos personajes.

La conjetura de la conciencia del otro, he aquí una de las constantes de una novela que por otra parte insiste a cada momento en los procedimientos del extrañamiento que ya propugnaban los formalistas rusos como recurso "desautomatizador" por excelencia. Ilustro lo anterior con este pasaje tomado de las escenas del asalto al cuartel de los fascistas. En medio de la acción el teléfono suena y Revueltas aprovecha el momento para evocar de modo irónico sus lecturas de Hegel:

Inesperadamente, se escuchó el timbre de un teléfono, allá abajo, en las oficinas de los fascistas. Un timbre tan vivo y universal como esas llamadas confusas y distantes que escuchan los mineros atrapados en el tiro de una mina cuando se aproxima la patrulla de rescate, o a la inversa, pero del mismo modo, cuando los tri- 
pulantes de un submarino que ya no podrá volver a la superficie, reciben el mensaje de que se ha hecho todo lo posible por salvarlos pero que deben resignarse a morir en paz y con honor. Repicaba sin cesar, una, dos, diez veces, apenas con una pausa anhelante e intranquila: un sonido con autoconsciencia de su ser. (Lo satisfactorio que hubiera sido tener un interlocutor a la mano para decírselo y sonreír juntos: un sonido que conocía la definición hecha de él por Hegel.) Parecía algo mágico, el juego de los "encantados" (308).

Más allá de esta curiosa referencia a Hegel, quizás debiera hablarse de un cripto-heideggerianismo de la narración. El concepto de Dasein, de "ser-ahî" en la traducción que se volvió canónica de José Gaos, pero equivalente al être-là por el que optaron los franceses, que enfatiza el ahi del ser, parece haber sido recogido por Revueltas en varios pasajes de su novela. Para empezar, y ya este dato me parece significativo, la novela arranca con la palabra "ahí", como se vio antes: "Ahí a sus espaldas...” La siguiente incursión, que transcribo, en la conciencia de Elena cuando éste se encuentra aprisionado en el interior de un veliz esperando el momento de salir en el despacho del viejo prestamista, puede corroborar mi sugerencia:

Se sentía seguro y feliz, un diminuto planeta en el espacio, vigilado y atendido por la cuidadosa solicitud de Dios, sometida a Él solo su abandonada voluntad. "Ahí lo vamos a poner». La voluptuosidad de no pertenecerse, de estar entregado, de no responder de sí mismo, de dejarse llevar de un lado al otro, a quién sabe dónde.

Ahi. ¿Qué podía significar esta palabra, ancha y abierta como el infinito? (43).

Es lo que a mí me gustaría preguntarme: ¿Qué significa la atención al ahí del ser en esta novela que, aunque escrita por un marxista, no puede escapar a los ecos del existencialismo heideggeriano? 


\section{Fuentes}

Fuentes Morúa, Jorge, 2001, José Revueltas. Una biografía intelectual, México, Miguel Ángel Porrúa/Universidad Autónoma Metropolitana-Iztapalapa.

García Flores, Margarita, 2001, "La libertad como conocimiento y transformación", en Andrea Revueltas y Philippe Cheron (comps.), Conversaciones con José Revueltas, México, Ediciones Era.

Hegel, G. W. F., 1966, Fenomenología del espiritu, Wenceslao Roces (trad.), México, FCE.

Kojéve, Alexandre, 2006, La idea de la muerte en Hegel, Juan José Sebreli (trad.), Buenos Aires, Leviatán.

Revueltas, José, 1964, Los errores, México, FCE, Colección: Letras Mexicanas núm. 78.

(Artículo recibido el 12 de marzo de 2014; aceptado el 25 de julio de 2014) 
